\title{
Time-dependent failure of amorphous polylactides in static loading conditions
}

\author{
Tom A. P. Engels · Serge H. M. Söntjens • \\ Theo H. Smit · Leon E. Govaert
}

Received: 23 June 2009/Accepted: 10 August 2009/Published online: 2 September 2009

(C) The Author(s) 2009. This article is published with open access at Springerlink.com

\begin{abstract}
Polylactides are commonly praised for their excellent mechanical properties (e.g. a high modulus and yield strength). In combination with their bioresorbability and biocompatibility, they are considered prime candidates for application in load-bearing biomedical implants. Unfortunately, however, their long-term performance under static load is far from impressive. In a previous in vivo study on degradable polylactide spinal cages in a goat model it was observed that, although short-term mechanical and real-time degradation experiments predicted otherwise, the implants failed prematurely under the specified loads. In this study we demonstrate that this premature failure is attributed to the time-dependent character of the material used. The phenomenon is common to all polymers, and finds its origin in stressactivated segmental molecular mobility leading to a steady rate of plastic flow. The stress-dependence of this flow-rate is well captured by Eyring's theory of absolute rates, as demonstrated on three amorphous polylactides of different stereoregularity. We show that the kinetics of the three materials are comparable and can be well described using the proposed modeling framework. The main conclusion is that knowledge of the instantaneous strength of a polymeric material is insufficient to predict its long-term performance.
\end{abstract}

T. A. P. Engels · S. H. M. Söntjens · L. E. Govaert $(\bowtie)$

Section Materials Technology (MaTe), Eindhoven University of Technology, 5600 MB Eindhoven, The Netherlands

e-mail: 1.e.govaert@tue.nl

\section{T. H. Smit}

Department of Physics and Medical Technology, VU University Medical Centre, 1007 MB Amsterdam, The Netherlands

\section{T. H. Smit}

Skeletal Tissue Engineering Group Amsterdam (STEGA), Amsterdam, The Netherlands

\section{Introduction}

Complications with metal implants and the frequency of revision surgeries has motivated the development of degradable polymer implants that have evident advantages over metal devices [1-4]: their stiffness is comparable to that of bone; they do not interfere with radiography, computer tomography, or magnetic resonance imaging [5]; and they degrade over time and thus eliminate the necessity of retrieval surgeries. In addition, the healing process may be stimulated by the successive loss of their mechanical properties, thereby gradually increasing the loads on the healing tissues. This concept of degradable polymers for skeletal tissue regeneration has been amply described, but its practical implementation remains challenging, in particular for load-bearing implants as used in trauma or spine.

Degradable polymers are interesting materials for surgical implants, but there are some caveats. First, polymer degradation can cause a severe host tissue response: late complications like osteolytic reactions have been reported with the use of different polyester implants [6-12]. Degradation and intensity of the inflammatory response are influenced by implant related factors (polymer type, purity, crystallinity, design, processing techniques), but also environment related factors (implantation site, vascularization, micro-motion, dynamic loading) [13-15]. Mechanical strength is a second concern of degradable polymers: the skeleton-in particular the spine and long bones-is subject to relatively large amplitudes of dynamic loading. Polymers not only have limited strength as compared to metals, but they also appear to degrade faster under such conditions [13-16]. Early loss of mechanical strength of the implants destabilizes the spinal segment, thus causing non-unions and clinical failure. A very important observation made in pre-clinical studies with respect to early loss of strength is 
the plastic deformation of implants made of 70/30 PLDLLA [17]. Implants which apparently had sufficient strength for bearing spinal loads during at least 8 months appeared to have been broken and deformed after only 3 months. It appeared in additional studies, that mechanical strength of 70/30 PLDLLA was lower for lower loading rates, higher temperature, and higher humidity [18]. Thus, 70/30 PLDLLA appears to show strong time- and load-dependent behaviour which is typical for glassy polymers [19].

This typical behaviour will be further investigated in this study on amorphous polylactides. Poly(lactic acid) is a thermoplastic, chiral polymer of which the L-enantiomer is the most occurring variant. An attractive feature is that the mechanical and degradation properties of poly(lactic acid) based polymers can be tailored to a large extent, i.e. polylactides can be made fully amorphous or semi-crystalline, based on their stereochemistry. For example, a D-enantiomer content of $15 \%$ or more leads to a fully amorphous material [20]. Also processing conditions play a role in the final properties of the product [21-23]. PLAs are generally characterized as materials with high moduli, but rather poor impact properties. Especially fully amorphous polylactides exhibit a low toughness and fail in a brittle manner in tension prior to reaching the yield point [20,24]. Plasticization, blending, co-polymerization and rubber toughening are common routes found to increase the toughness of the material [25-29], but also orientation of the polymer chains, i.e. cold- and hot-drawing (fiber spinning), is a route to improvement $[24,30]$.

In this study we investigate the deformation kinetics of three amorphous polylactides of different stereoregularity. First, the phenomenology of time-dependent failure is discussed and illustrated. Next the origin of this behaviour is elucidated. Subsequently, the time-dependent behavior of the three polylactides is quantified in a series of shortand long-term loading experiments and described by a well established phenomenological model. It will be shown that the time-dependency of glassy polylactides is very strong, explaining the early failure of implants under static loading conditions.

\section{Materials and methods}

\subsection{Materials}

The materials used in this study are a stereoregular poly(Llactic acid) homopolymer (PLLA), a 70/30 copolymer of poly(L-lactic acid) with a stereoirregular poly(D,L-lactic acid) copolymer (PLDLLA), and a racemic poly(D,L-lactic acid) copolymer (PDLLA). All materials were kindly provided by PURAC Biochem (Gorinchem, The Netherlands).
The initial inherent viscosities (IV $0.1 \mathrm{~g} / \mathrm{dl} \mathrm{CHCl}_{3}$ ) of the materials as determined by the supplier are $7.37 \mathrm{dl} / \mathrm{g}$ for the PLDLLA, $8.28 \mathrm{dl} / \mathrm{g}$ for the PLLA, and $4.20 \mathrm{dl} / \mathrm{g}$ for the PDLLA.

For compression testing granules were compression molded into $10 \mathrm{~mm}$ thick rectangular plaques at $200^{\circ} \mathrm{C}$ and successively cooled rapidly to room temperature by water cooled plates. From the compression molded plaques, cylinders with a diameter and height of $6 \mathrm{~mm}$ were machined. For dynamical mechanical thermal analysis (DMTA) small plates of $1 \mathrm{~mm}$ thickness were compression molded. From these plates, bars of $1 \times 5 \times 20 \mathrm{~mm}^{3}$ were cut. During all machining operations the materials were cooled by air.

\subsection{Methods}

Compressive experiments are used rather than tensile ones, since in extension amorphous polylactides behave brittle $[20,24]$, obstructing the investigation of the large strain response which governs the macroscopic behavior [31, 32]. Also the prematurely failing spinal implants [17], which triggered this investigation, were loaded in compression.

Compression testing was performed on a servohydraulic MTS Elastomer Testing System 831 equipped with a temperature chamber at 0,25 and $37^{\circ} \mathrm{C}$. Friction between samples and compression platens was reduced by applying a thin film of skived PTFE tape (3M 5480) on the sample ends and spraying PTFE lubricant on the compression platens. Constant strain rate experiments were executed in true strain control at rates of $10^{-2}, 10^{-3}$ and $10^{-4} \mathrm{~s}^{-1}$. Creep experiments were performed in true stress control at various stress levels. All loads were applied within $5 \mathrm{~s}$. True stresses and true strains were calculated under the assumption of incompressibility.

Dynamical Mechanical Thermal Analysis (DMTA) was performed on a TA Instruments Q800 in film tension mode at $1 \mathrm{~Hz}$ from -100 to $200^{\circ} \mathrm{C}$ at an underlying heating rate of $3^{\circ} \mathrm{C} / \mathrm{min}$

Differential scanning calorimetry (DSC) was performed on a Mettler Toledo DSC823e equipped with a FRS5 sensor. Calibration was done using the melting peaks of indium, lead, tin, zinc, benzophenone and benzoic acid. Scans were performed from 0 to $200^{\circ} \mathrm{C}$ with an underlying heating rate of $10^{\circ} \mathrm{C} / \mathrm{min}$.

\section{Results and discussion}

\subsection{Thermal analysis}

Before discussing the phenomenology and modeling of the mechanical behavior of the amorphous polylactides, it is 
Fig. 1 Thermal analysis of the polylactides investigated. Left: DSC. Right: DMTA
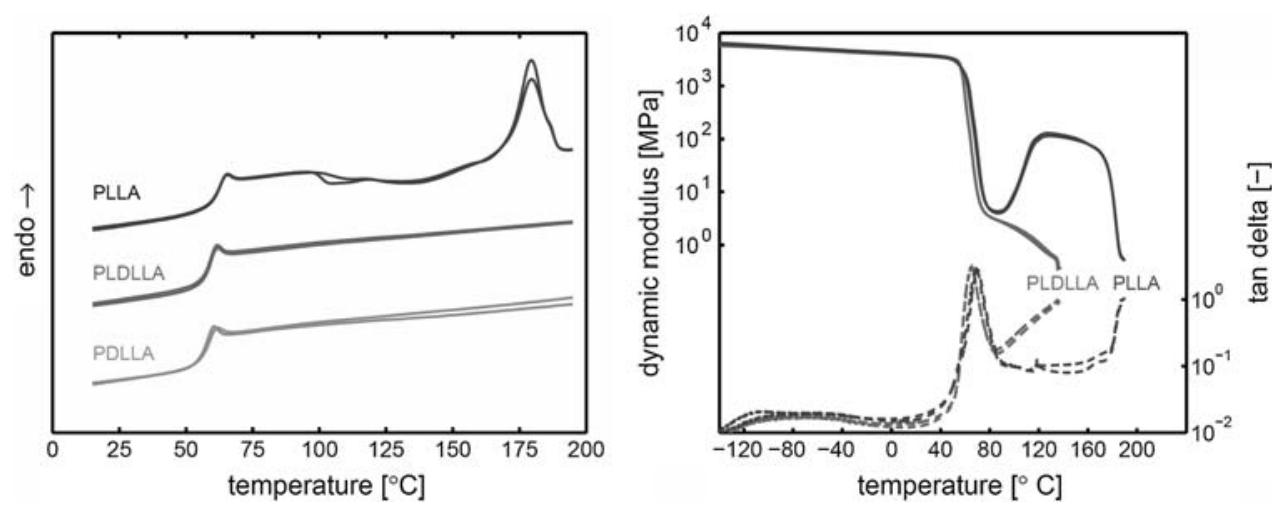

confirmed that the materials are fully amorphous by means of Differential Scanning Calorimetry (DSC) and Dynamical Mechanical Thermal Analysis (DMTA). Figure 1 (left) shows DSC heating traces measured at $10^{\circ} \mathrm{C} / \mathrm{min}$. The PLDLLA and PDLLA show no crystalline behavior at all and can be regarded $100 \%$ amorphous, which is as expected since the D-enantiomer content is $15 \%$ or more [20]. The stereoregular PLLA by contrast shows marked exo- and endo-thermic peaks indicating that crystallization does occur. The net value of the heat lost during crystallization and the heat regained during melting accounts to zero, indicating that no, or at least a negligible, crystalline fraction is present in the initial material and that the crystallization phenomena observed in the DSC experiments can be attributed to the experimental routine itself. This is confirmed by the DMTA experiments, performed only on the PLLA and PLDLLA, which show that the initial moduli of the two materials are identical within experimental uncertainty and the drop in moduli, upon passing the glass transition, are similar. Small fractions of crystallinity would be evidenced by an increase in the modulus both in the glassy and in the rubbery state [33]. Moreover the material was as transparent as the PLDLLA and PDLLA samples at the start of any experiment, another indication that the material is amorphous after compression molding. In accordance with the DSC experiments the glass transition temperature found by DMTA is higher for the PLLA, see Table 1. The upswing in modulus observed for the PLLA above its glass transition temperature $\left(T_{\mathrm{g}}\right)$ is a result of cold crystallization induced by the measurement itself and reported in literature [34, 35]. The higher glass transition temperature of the PLLA in comparison to the

Table 1 Glass transition temperatures

\begin{tabular}{lll}
\hline$T_{\mathrm{g}}$ & DSC $\left({ }^{\circ} \mathrm{C}\right)$ & DMTA $\left({ }^{\circ} \mathrm{C}\right)$ \\
\hline PLLA & 61 & 70 \\
PLDLLA & 58 & 65 \\
PDLLA & 57 & - \\
\hline
\end{tabular}

PLDLLA and PDLLA can be explained by an increased mobility of the PLDLLA chains due to their less stereoregular buildup [34, 36].

\subsection{Phenomenology}

To illustrate the time-dependent failure of glassy polymers, first the behavior of PLLA in compression under a variety of applied strain rates and stresses is examined. Figure 2 (left) shows the true stress versus true strain response, i.e. the intrinsic behavior, for PLLA as measured under compression at a constant true strain rate, resulting in homogeneous deformation over large strains. Initially the material behavior is linear visco-elastic, but at increasing stress levels it becomes strongly nonlinear, eventually reaching a maximum, i.e. the yield stress (here at $4 \%$ strain and a stress of approximately $94 \mathrm{MPa}$ ). Subsequently two characteristic phenomena are encountered: (1) strain softening, the initial decrease of true stress with strain and (2) strain hardening, the subsequent upswing of the true stressstrain curve [19]. The interplay between strain softening and strain hardening, to a large extend, determines the toughness of a material, where materials with strong softening and weak hardening behave brittle, and materials with weak softening and strong hardening tough [31, 32]. The strong strain softening and very weak strain hardening found in Fig. 2 (left), is therefore in full accordance with the brittle nature of PLA.

That failure of glassy polymers is strongly time-dependent becomes evident when a constant stress is applied on a similar sample, see Fig. 2 (right), at a stress of $65 \mathrm{MPa}$ which is $30 \%$ below the yield stress as measured in Fig. 2 (left). Initially the sample reacts with an elastic response resulting in a few percent of strain, after which the deformation increases gradually with time, resulting after a short while in a constant rate of strain. At longer loading times the strain rate increases and eventually leads to failure of the sample in little more than half an hour. Failure is here taken as the moment at which the material deforms plastically over large strains, essentially loosing its structural 
Fig. 2 Left: Compressive true stress versus strain measured at a constant true strain rate. Right: Compressive true strain versus loading time measured under a constant stress
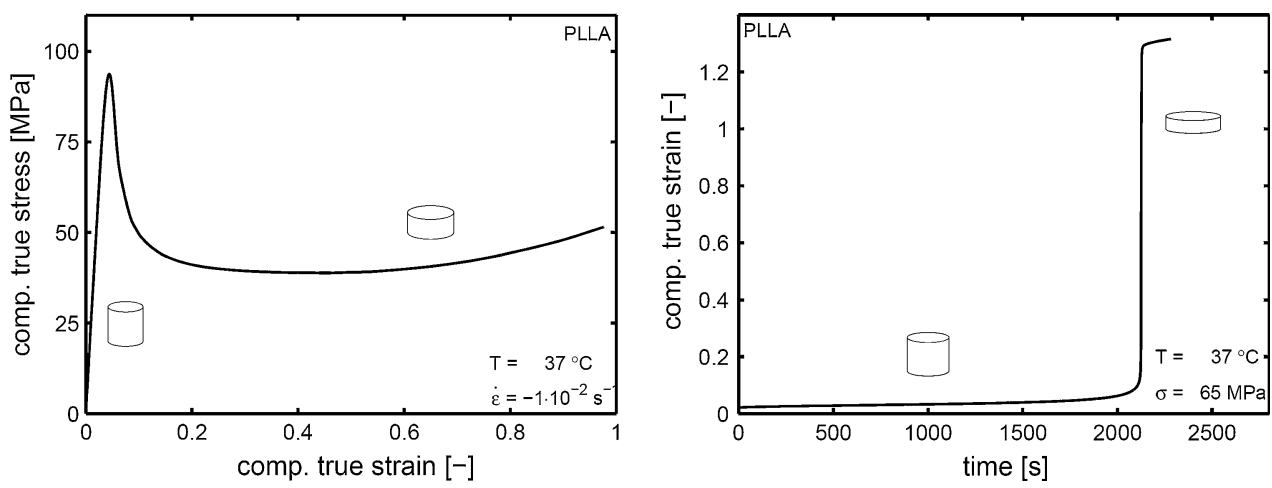

stability. In tension, at the time-of-failure, a sample can show necking similar to that observed in a constant strain rate experiment when passing the yield point. Therefore, ductile failure under a constant stress, since the moment of localization can take considerable time, depending on the applied load, is also called delayed yielding.

This time-dependent response of the material strongly depends on the loading conditions applied. Figure 3 shows the true strain versus loading time for four different loads (left). By increasing the loads, time-to-failure can be significantly decreased. When the applied stresses are plotted versus the corresponding times-to-failure, a semi logarithmic relation is observed, where a decrease in applied stress of about $14 \mathrm{MPa}(\alpha)$ leads to an increase in lifespan by an order of ten. From this the conclusion can be drawn that it is not the question whether the material will fail under a static load, but rather when it will fail under the specified load.

\subsection{Origin}

The origin of this kinetics, i.e. the time-dependent behavior, can be related to the molecular structure of the material. Amorphous polymers consist of long, covalently-bonded molecules that are randomly distributed throughout the material. Each molecule has the ability to change its spatial conformation by rotation around covalent bonds that form the back-bone of the chain, and in its equilibrium state this will be the most probable conformation: a random coil. The rate at which a chain can change its conformation depends strongly on temperature. At high temperature conformational changes are fast and the chains can move freely with applied deformation (melt-like behavior). At low temperature (below the glass transition temperature), chain mobility decreases drastically and the material "vitrifies" [37] (becomes glass-like). However, changes in chain conformation are still feasible, albeit that the associated timescale is long, as the mobility of the chains is very low. The application of stress changes this picture drastically, since similar to temperature, stress significantly enhances mainchain mobility, leading to mobility similar to the melt-state. The deformation behavior can therefore be seen as a sort of fluid-like behavior, albeit a fluid with a very high viscosity.

To illustrate this, the yield point is investigated a bit closer. From literature it is well known that the yield point is observed to increase with increasing strain rate and decreasing temperature, and the increase with strain rate is demonstrated here in Fig. 4 (left) for three strain rates. Plotting the yield stresses against the applied strain rate results again in a semi-logarithmic relation, see Fig. 4 (right). In the initial stage of loading, where the stress is still low, chain mobility is negligible, and the modulus is determined by the intermolecular interactions between individual chains. With increasing stress the chain mobility increases, and changes in chain conformation gradually start to contribute to the deformation of the material. This
Fig. 3 Left: True strain versus loading time for increasing stresses. Right: Stress dependence of the time-tofailure
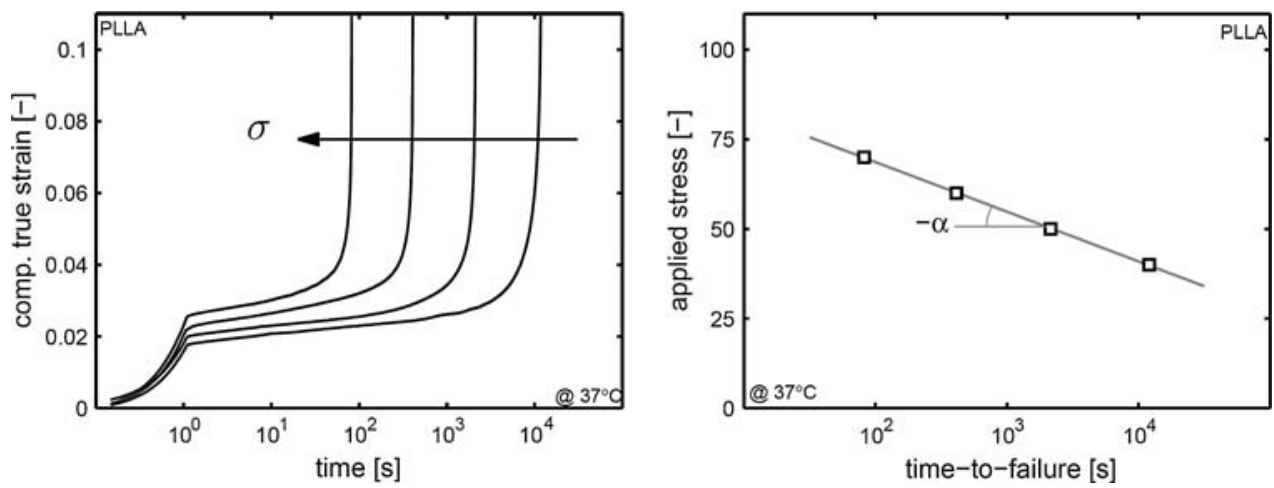
Fig. 4 Left: True stress versus strain for increasing strain rates. Right: Rate dependence of the yield stress
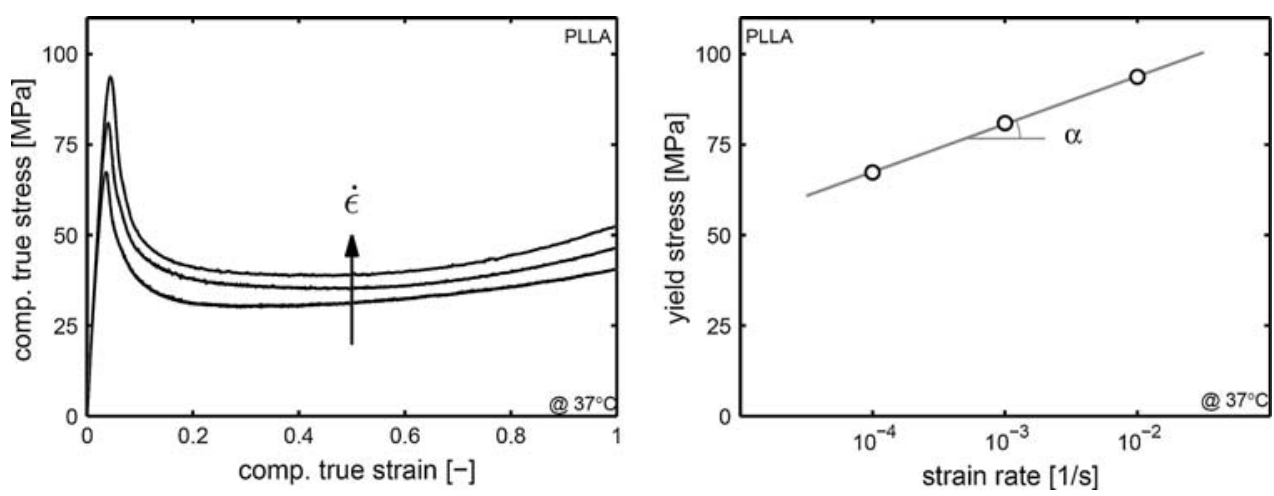

contribution progressively increases, until it reaches a stress level where the plastic strain rate resulting from chain mobility matches the one experimentally applied; the yield stress. In other words, applied stress induces a state of enhanced molecular mobility that stimulates a dynamic rearrangement of molecular segments, resulting in a steady rate of plastic flow. The magnitude of this plastic flow rate depends on the applied stress and temperature. At higher strain rates, a higher stress level is necessary to obtain the mobility required to balance the plastic flow rate with the applied rate. As a result the yield stress is observed to increase with increasing strain rate (Fig. 4, right).

This steady rate of plastic flow can also be found under static stress, e.g. in the creep curves of Fig. 3 (left). From these creep curves the evolution of strain rate versus strain is plotted in a so-called Sherby-Dorn plot [38], see Fig. 5 (left). Here it is observed that at each load the strain rate initially decreases (primary creep), reaches a minimum (secondary creep), and subsequently increases again (tertiary creep). During secondary creep a steady rate of plastic flow is observed, which is sometimes referred to as "plateau creep rate". In the case of PLLA, the strain range in which steady flow occurs is rather small (compared to PMMA [38] or PC [39]), but, as a result of the low strain rate, it will manifest itself over a considerable time span. It was first demonstrated by Bauwens-Crowet et al. [39] that the steady state of flow obtained in static loading during secondary creep is identical to that obtained at the yield stress in a constant strain rate experiment. This is demonstrated in Fig. 5 (right), that presents the steady state values of stress and strain rate obtained from tensile tests at constant strain rate and creep testes under static load. Both yield exactly the same curve and the absolute values of the slopes of Figs. 3 (right) and 4 (right) are the same.

In summary, the results indicate that applied stress induces a state of enhanced molecular mobility in polymer glasses which results in a steady rate of plastic flow. In the following, this behavior will be analyzed quantitatively for three amorphous polylactides and described using a well established modeling framework.

\subsection{Modeling}

In the preceding section it was established that at the yield stress, glassy polymers exhibit viscous flow. This was already realized some 50 years ago by several authors who took Eyring's theory of absolute rates [40] to describe the dependence of the yield stress on applied strain rate and temperature [41, 42]. The same theory was also applied to describe the creep failure of polymeric filaments, which also show a semi-logarithmic relationship between the load applied and the time-to-failure [43]. The strong resemblance of the mode of ductile failure, i.e. necking, found in
Fig. 5 Left: Evolution of the strain rate during creep at various loads (derived form the data in Fig. 2 (right)). Right: Stress as a function of strain rate. Tensile experiments (open markers), creep experiments (closed markers)
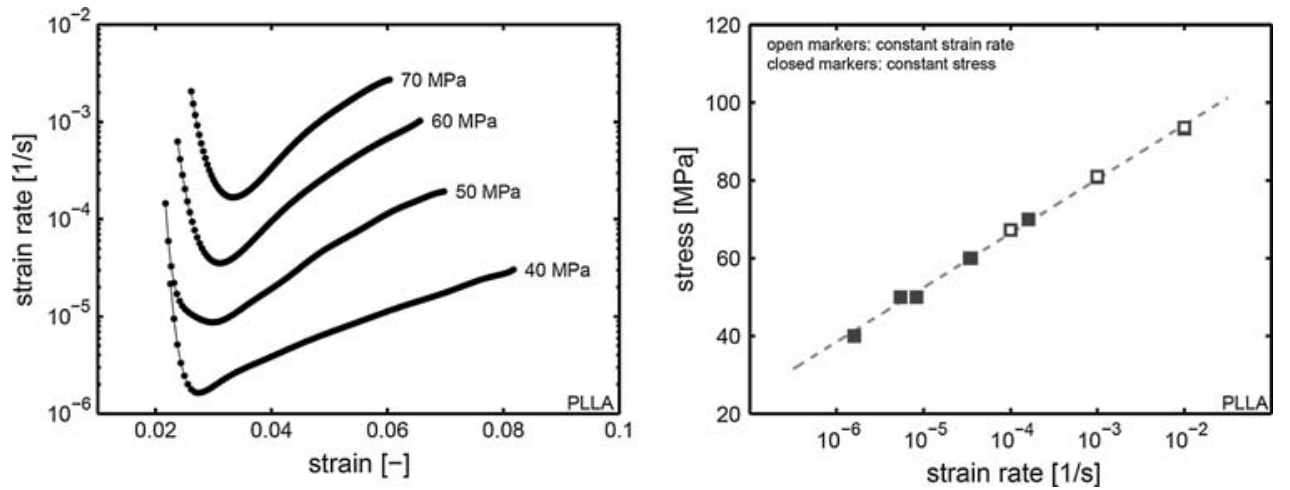
tension between samples loaded with a constant strain rate or a constant stress, led some authors to also apply Eyring's equation to the dependence of the time-to-failure on the applied stress [39, 44]. They observed good agreement between the rate determining parameters found under a applied strain rate and applied stress.

Eyring's equation applied to the viscous flow during yielding of polymers is given by $[40,45]$ :

$\dot{\varepsilon}(\sigma, T)=\dot{\varepsilon}_{0}^{*}(T) \cdot \sinh \left(\frac{\sigma \cdot V^{*}}{k \cdot T}\right)$

where

$\dot{\varepsilon}_{0}^{*}=\dot{\varepsilon}_{0} \cdot \exp \left(-\frac{\Delta U}{R \cdot T}\right)$

in which $\dot{\varepsilon}$ is the strain rate $\left(\mathrm{s}^{-1}\right), \dot{\varepsilon}_{0}^{*}$ a reference strain rate at an arbitrary temperature $\left(\mathrm{s}^{-1}\right), \sigma$ the stress $(\mathrm{Pa}), T$ the absolute temperature $(\mathrm{K}), V^{*}$ the activation volume $\left(\mathrm{m}^{3}\right), k$ Boltzmann's constant $(\mathrm{J} / \mathrm{K}), \dot{\varepsilon}_{0}$ the absolute reference strain rate $\left(\mathrm{s}^{-1}\right)$ and $\Delta U$ the activation energy $(\mathrm{J} / \mathrm{mol})$.

In the case of an applied constant strain rate, Eq. 1 can be rewritten to [45]:

$\sigma(\dot{\varepsilon}, T)=\frac{k \cdot T}{V^{*}} \cdot \sinh ^{-1}\left(\frac{\dot{\varepsilon}}{\dot{\varepsilon}_{0}^{*}(T)}\right)$

in which $\dot{\varepsilon}$ is the applied strain rate, and $\sigma$ the resulting yield stress.
In case of an applied constant stress, Eq. 1 can, with the introduction of a critical accumulated plastic strain, $\varepsilon_{c r}$ [39, 46], be rewritten to:

$t_{f}(\sigma, T)=\frac{\varepsilon_{c r}}{\dot{\varepsilon}(\sigma, T)}=\frac{\varepsilon_{c r}}{\dot{\varepsilon}_{0}^{*}(T)} \cdot\left[\sinh \left(\frac{\sigma \cdot V^{*}}{k \cdot T}\right)\right]^{-1}$

in which $\sigma$ is the applied constant stress and $\dot{\varepsilon}$ is the resulting plastic strain rate.

Figures 6, 7 and 8 show the yield stress versus the applied strain rate (left) and applied stress versus the timeto-failure (right) for all three polylactides at different temperatures. The lines drawn in these figures are obtained by fitting Eqs. 3 and 4 to the data of all three polylactides simultaneously, by means of a least squares approach, resulting in a single parameter set, see Table 2 . The only parameter allowed to vary for each material is the absolute reference strain rate, $\dot{\varepsilon}_{0}$, which depends on the thermomechanical history of the material and the relative undercooling with respect to $T_{\mathrm{g}}$ [19]. The resulting values for $\dot{\varepsilon}_{0}$ are $2.33 \times 10^{22}, 1.64 \times 10^{23}$ and $4.69 \times 10^{22} \mathrm{~s}^{-1}$ for the PLLA, PLDLLA and PDLLA, respectively. The resulting fits are found to describe the experimental data quite well. The fact that the rate determining parameters for these materials are, within experimental error, the same, corresponds well to observations in other studies in which the apparent activation energy of the glass transition temperature is found to be the same [35, 47]. Yielding of polymers
Fig. 6 PLLA. Left: Yield stress versus applied strain rate. Right: Applied stress versus time-tofailure. Lines are drawn using Eqs. 3 and 4, with the parameters listed in Table 2
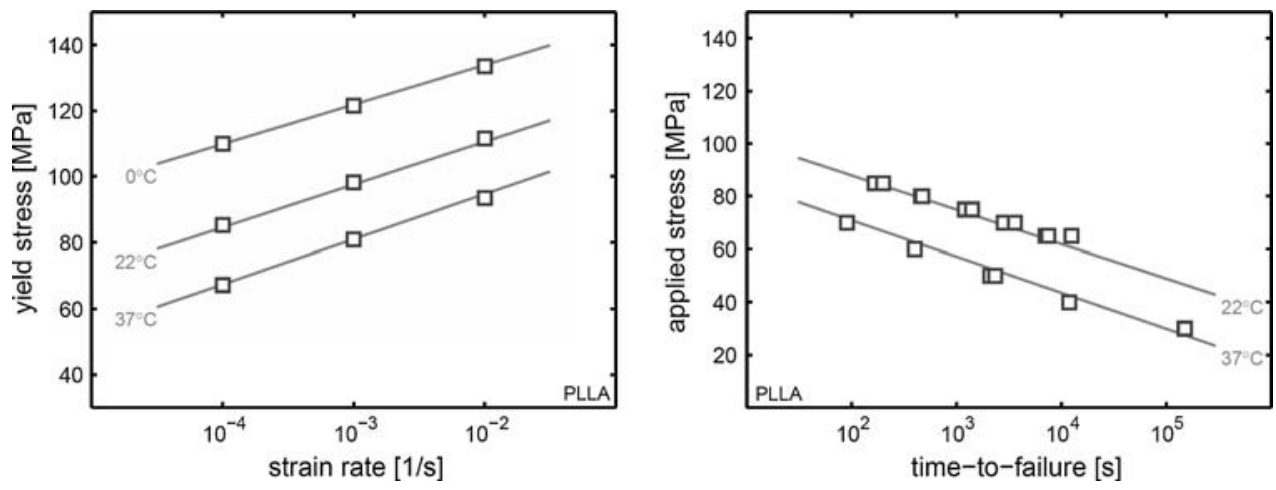

Fig. 7 PLDLLA. Left: Yield stress versus applied strain rate. Right: Applied stress versus time-to-failure. Lines are drawn using Eqs. 3 and 4, with the parameters listed in Table 2
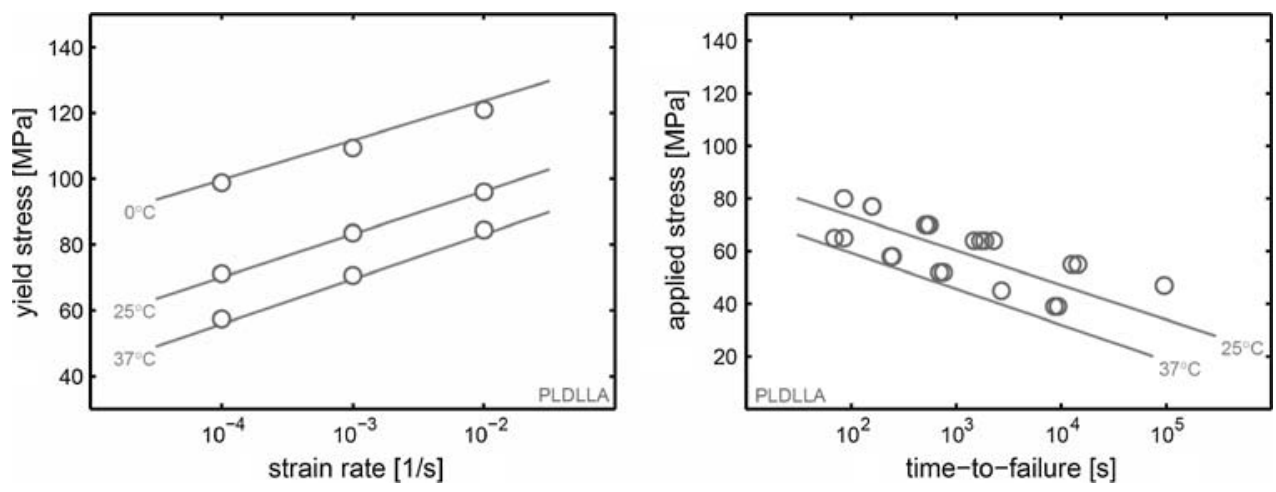
Fig. 8 PDLLA. Left: Yield stress versus applied strain rate. Right: Applied stress versus time-to-failure. Lines are drawn using Eqs. 3 and 4, with the parameters listed in Table 2
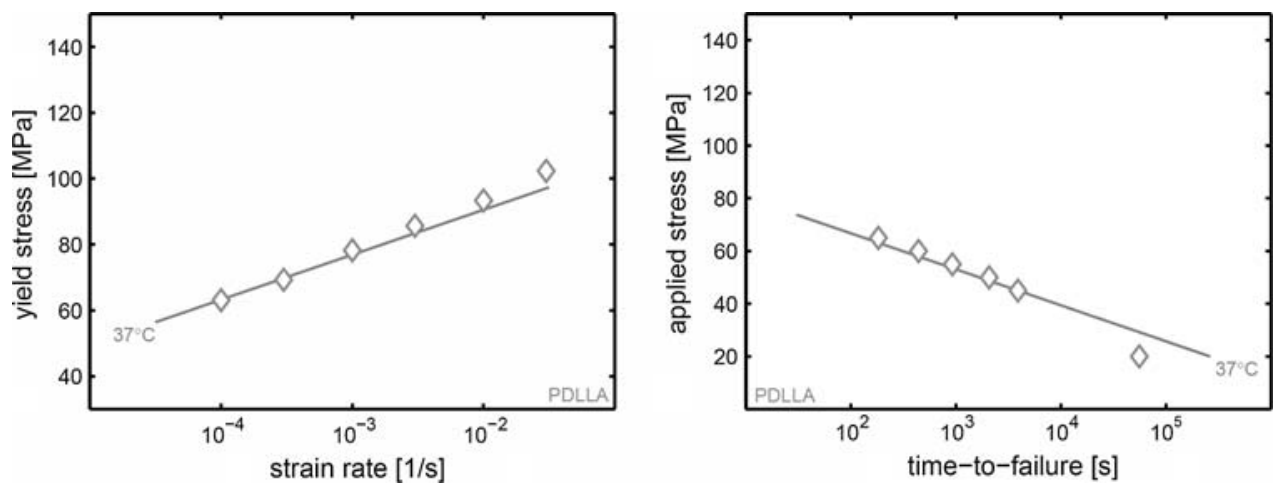

Table 2 Eyring parameters

\begin{tabular}{lll}
\hline$V^{*}\left(\AA^{3}\right)$ & $\Delta U(\mathrm{~kJ} / \mathrm{mol})$ & $\varepsilon_{c r}(\%)$ \\
\hline 722 & 184 & 1.8 \\
\hline
\end{tabular}

is often regarded as the mechanical equivalent of the glass transition, i.e. the influence of physical aging on the increase in yield stress and increase in enthalpy recovery have been shown to be proportionally related $[48,49]$, and the kinetics of both processes may, therefore, be expected to at least show the same qualitative behavior.

\section{Discussion}

Activation volume $V^{*}$ in Eqs. 3 and 4 captures the rate dependence of the material, i.e. slopes $\alpha$ and $-\alpha$ of Figs. 3 and 4 (right). For the three polylactides at $37^{\circ} \mathrm{C}$ the value of $\alpha$ is found to be $\pm 14 \mathrm{MPa}$ /decade. When comparing this value with that of-for instance-polycarbonate (PC; 3-4 MPa/decade [19, 50, 51]), or poly(etheretherketone) (PEEK; 4 MPa/decade [52]; another in the field of biomedical implants often used semi-crystalline biocompatible polymer), it can be concluded that the rate dependence of PLA is rather high. Actual comparison of the time-dependent behavior of PLLA with that of PC is given in Fig. 9. Although the strength of the PLLA as measured under an applied strain rate is higher than that of $\mathrm{PC}$, the static fatigue properties of PC already outperforms those of PLLA at about $3 \mathrm{~h}$. This illustrates that knowledge of the instantaneous strength of a polymeric material is insufficient to predict its applicability under load over long times.

Despite the excellent short-term properties of PLLA, its lifetime under a static stress of $50 \mathrm{MPa}(50 \%$ of the shortterm strength) is only little more than a single day. In comparison, the lifetime of PC under the same load of $50 \mathrm{MPa}$ ( $76 \%$ of the short-term strength) is over 3 months! This is actually the expected lifetime of PLLA at a static load of only $25 \%$ of its short-term strength. From a quantitative point of view it is quite clear that the long-term performance of PLLA is worrying. An additional problem is that water acts as a plasticizer, and, as a result, the loadbearing capacity further decreases. Observations on PLDLLA spinal cages showed that the effect of wetting is similar to that of an increase in temperature [18].

Summarizing, the strong time-dependent mechanical behavior of PLDLLA spinal cages found in our previous study [18], clearly finds its origin in the intrinsic deformation kinetics of the material. The strong dependence of the maximum force on the loading rate applied during the compression of a spinal cage is in good agreement with the strong increase in yield stress with applied strain rate observed in this study. Increasing the loading velocity of the spinal cages with a factor of 10 resulted in an increase of the maximum force of $0.86 \mathrm{kN}$ at room temperature.
Fig. 9 Uniaxial compression results for PLLA and PC. Left: Yield stress versus strain rate. Right: Time-to-failure versus applied stress
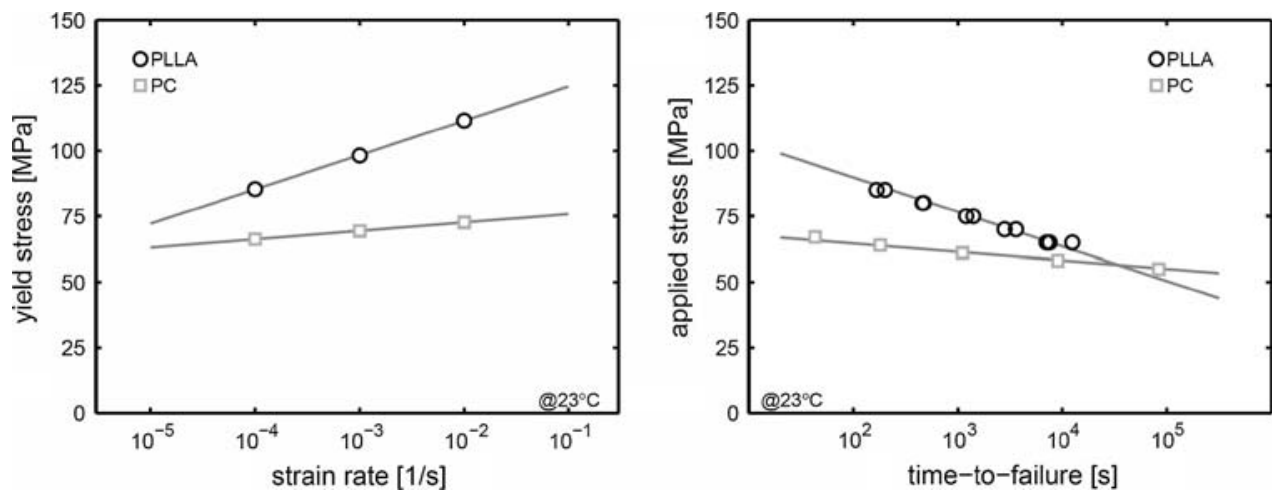
Dividing this increase in force per decade of loading rate by the cross-sectional area of the spinal cages (approximately $70 \mathrm{~mm}^{2}$ ) results in an increase of $12.3 \mathrm{MPa} /$ decade. The increase in yield stress with applied strain rate, as found in this study for amorphous PLAs, matches the results on the spinal cages very well. The premature failure of the spinal cages can therefore be directly attributed to the strong deformation-rate dependence of polylactides.

We must hasten to add that the PLAs studied here are all fully amorphous, and, consequently, the results obtained may not be representative for a partly crystalline PLA. Of course, even in a semi-crystalline PLA, the amorphous phase will display a response identical to the amorphous PLAs studied here. The additional stress contribution of the crystalline phase, however, might show different kinetics that may lead to improved long-term performance. For low levels of crystallinity such an improvement is not anticipated.

The modeling framework used in this study is essentially an analytical 1D approach suitable only for simple loading geometries. A more advanced 3D constitutive framework to describe the complete large strain deformation behavior of polymer glasses is available in a Finite Element Method (FEM) implementation [19, 53], and the parameters determined in this study can serve as initial input for this more elaborate model. With the use of the FEM model even 'complex' geometries can be quantitatively evaluated to guaranty proper design and prevent unexpected mechanical failure due to the materials intrinsic time-dependent character [54].

\section{Conclusions}

It was established that glassy polymers can best be regarded as highly viscous fluids. Upon application of stress a state of enhanced molecular mobility is induced that stimulates a dynamic rearrangement of molecular segments, resulting in a steady rate of plastic flow. This deformation can propagate at this steady pace until strain softening sets in, accelerating the rate of deformation initiating a localized plastic deformation zone: failure occurs.

To gain more insight in the premature failure of spinal implants made of amorphous polylactides, the intrinsic deformation kinetics of three polylactides with different stereoregularities have been determined over a range of temperatures and strain rates. The deformation kinetics of amorphous PLA appears independent of stereoregularity, and is described well with Eyring's flow theory. The timesto-failure measured under constant applied stress are shown to be governed by the same kinetics as found for the constant applied strain rate experiments.
Remarkably, the rate-dependence of the yield stress of amorphous PLA is found to be very high when compared to other materials frequently used in medical applications. The poor performance in static loading, observed in spinal implants, is directly linked to this strong rate dependence. The main conclusion is that knowledge of the instantaneous strength of a polymeric material is insufficient to predict its applicability under load over long times.

Acknowledgements The authors thank PURAC Biochem (Gorinchem, The Netherlands) for providing the materials and the students J.W. Sturm (Stefan) and E. Tellier (Eric) for the help with the experimental work. The authors are grateful to the Dutch Polymer Institute (DPI) for financially support (grant \#614).

Open Access This article is distributed under the terms of the Creative Commons Attribution Noncommercial License which permits any noncommercial use, distribution, and reproduction in any medium, provided the original author(s) and source are credited.

\section{References}

1. van Dijk M, Smit TH, Burger EH, Wuisman PI. Bioabsorbable poly-L-lactic acid cages for lumbar interbody fusion: three-year follow-up radiographic, histologic, and histomorphometric analysis in goats. Spine. 2002;27:2706-14.

2. Wuisman PI, van Dijk M, Smit TH. Resorbable cages for spinal fusion: an experimental goat model. J Neurosurg. 2002;97:433-9.

3. van Dijk M, Tunc DC, Smit TH, Higham P, Burger EH, Wuisman PIJM. In vitro and in vivo degradation of bioabsorbable PLLA spinal fusion cages. J Biomed Mater Res. 2002;63:752-9.

4. van Dijk M, Smit TH, Arnoe MF, Burger EH, Wuisman PI. The use of poly-L-lactic acid in lumbar interbody cages: design and biomechanical evaluation in vitro. Eur Spine J. 2003;12:34-40.

5. Cordewener FW, Bos RR, Rozema FR, Houtman WA. Poly(Llactide) implants for repair of human orbital floor defects: clinical and magnetic resonance imaging evaluation of long-term results. J Oral Maxillofac Surg. 1996;54:9-13.

6. Rokkanen PU, Bostman O, Hirvensalo E, Makela EA, Partio EK, Paiala H, et al. Bioabsorbable fixation in orthopaedic surgery and traumatology. Biomaterials. 2000;21:2607-13.

7. Partio EK, Bostman O, Hirvensalo E, Vainionpaa S, Vihtonen K, Patiala $\mathrm{H}$, et al. Self-reinforced absorbable screws in the fixation of displaced ankle fractures: a prospective clinical study of 152 patients. J Orthop Trauma. 1992;6:209-15.

8. Bergsma EJ, Rozema FR, Bos RR, de Bruijn WC. Foreign body reactions to resorbable poly(L-lactide) bone plates and screws used for the fixation of unstable zygomatic fractures. J Oral Maxillofac Surg. 1993;51:666-70.

9. Bostman OM. Osteoarthritis of the ankle after foreign-body reaction to absorbable pins and screws: a three- to nine-year follow-up study. J Bone Joint Surg Br. 1998;80:333-8.

10. Bostman OM, Pihlajamaki HK. Late foreign-body reaction to an intraosseous bioabsorbable polylactic acid screw. A case report. J Bone Joint Surg Am. 1998;80:1791-4.

11. Bergsma JE, de Bruijn WC, Rozema FR, Bos RRM, Boering G. Late degradation tissue response to poly(L-lactide) bone plates and screws. Biomaterials. 1995;16:25-31.

12. Bostman OM, Pihlajamaki HK. Adverse tissue reactions to bioabsorbable fixation devices. Clin Orthop Relat Res. 2000;(371): 216-27. 
13. Middleton JC, Tipton AJ. Synthetic biodegradable polymers as orthopedic devices. Biomaterials. 2000;21:2335-46.

14. Bostman O, Pihlajamaki H. Clinical biocompatibility of biodegradable orthopaedic implants for internal fixation: a review. Biomaterials. 2000;21:2615-21.

15. Vert M. Poly(lactic acid)s. In: Wnek GE, Bowlin GL, editors. Encyclopedia of biomaterials and biomedical engineering. New York: Marcel Dekker, inc.; 2004. p. 1254-64.

16. Athanasiou KA, Agrawal CM, Barber FA, Bukhart SS. Orthopaedic applications for PLA-PGA biodegradable polymers. Arthroscopy. 1998;14:726-37.

17. Krijnen MR, Mullender MG, Smit TH, Everts V, Wuisman PIJM. Radiographic, histologic, and chemical evaluation of bioresorbable 70/30 poly-L-lactide-CO-D,L-lactide interbody fusion cages in a goat model. Spine. 2006;31:1559-67.

18. Smit TH, Engels TAP, Wuisman PI, Govaert LE. Time-dependent mechanical strength of 70/30 Poly(L, DL-lactide): shedding light on the premature failure of degradable spinal cages. Spine. 2008;33:14-8.

19. Klompen ETJ, Engels TAP, Govaert LE, Meijer HEH. Modeling of the postyield response of glassy polymers: influence of thermomechanical history. Macromolecules. 2005;38:6997-7008.

20. Grijpma DW, Pennings AJ. (Co)polymers of L-lactice, 2 mechanical properties. Macromol Chem Phys. 1994;195:1649-63.

21. Perego G, Cella GD, Bastioli C. Effect of molecular weight and crystallinity on poly(lactic acid) mechanical properties. J Appl Polym Sci. 1996;59:37-43.

22. Sarasua JR, López Arraiza A, Balerdi P, Maiza I. Crystallinity and mechanical properties of optical pure polylactides and their blends. Polym Eng Sci. 2005;45:745-53.

23. Li H, Huneault MA. Effect of nucleation and plasticization on the crystallization of poly(lactic acid). Polymer. 2007;48:6855-66.

24. Grijpma DW, Altpeter H, Bevis MJ, Feijen J. Improvement of the mechanical properties of poly(D,L-lactide) by orientation. Polym Int. 2002;51:845-51.

25. Jacobsen S, Fritz HG. Plasticizing polylactide-the effect of different plasticizers on the mechanical properties. Polym Eng Sci. 1999;39:1303-10.

26. Martin O, Avérous L. Poly(lactic acid): plasticization and properties of biodegradable multiphase systems. Polymer. 2001;42: 6209-19.

27. Shibata M, Teramoto N, Inoue Y. Mechanical properties, morphologies, and crystallization behavior of plasticized poly (L-lactide)/poly(butylene succinate-co-L-lactate) blends. Polymer. 2007;48:2768-77.

28. Li Y, Shimizu H. Toughening of polylactide by melt blending with a biodegradable poly(ether)urethane elastomer. Macromol Biosci. 2007;7:921-8.

29. Grijpma DW, van Hofslot DA, Supèr H, Nijenhuis AJ, Pennings AJ. Rubber toughening of poly(lactide) by blending and block copolymerization. Polym Eng Sci. 1994;34:1674-84.

30. Grijpma DW, Penning JP, Pennings AJ. Chain entanglement, mechanical properties and drawability of poly(lactide). Colloid Polym Sci. 1994;272:1068-81.

31. Meijer HEH, Govaert LE. Mechanical performance of polymer systems: the relation between structure and properties. Prog Polym Sci. 2005;30:915-38.

32. van Melick HGH, Govaert LE, Meijer HEH. Localisation phenomena in glassy polymers: influence of thermal and mechanical history. Polymer. 2003;44:3579-91.
33. Boyd RH. Relaxation processes in crystalline polymers: experimental behaviour - a review. Polymer. 1985;26:323-47.

34. Urayama H, Kanamori T, Kimura Y. Microstructure and thermomechanical properties of glassy polylactides with different optical purity of the lactate units. Macromol Mater Eng. 2001;286:705-13.

35. Pan P, Zhu B, Inoue Y. Enthalpy relaxation and embrittlement of poly(L-lactide) during physical aging. Macromolecules. 2007; 40:9664-71.

36. Joziasse CAP, Veenstra H, Grijpma DW, Pennings AJ. On the chain stiffness of poly(lactide)s. Macromol Chem Phys. 1996; 197:2219-29.

37. McKenna GB. Glass formation and glassy behavior. In: Booth C, Price C, editors. Comprehensive polymer science, vol. 2: polymer properties, Ch. 10. Oxford: Pergamon; 1989, p. 311-62.

38. Sherby OD, Dorn JE. Anelastic creep of PMMA. J Mech Phys Solids. 1954;6:145-62.

39. Bauwens-Crowet C, Ots J-M, Bauwens J-C. The strain-rate and temperature dependence of yield of polycarbonate in tension, tensile creep and impact tests. J Mater Sci Lett. 1974;9:1197-2101.

40. Eyring H. Viscosity, plasticity, and diffusion as examples of absolute reaction rates. J Chem Phys. 1936;4:283-91.

41. Robertson RE. On the cold-drawing of plastics. J Appl Polym Sci. 1963;7:443-50.

42. Bauwens-Crowet $\mathrm{C}$, Bauwens J-C, Homès G. Tensile yield-stress behavior of glassy polymers. J Polym Sci: Part A-2 1969;7:735-42.

43. Coleman BD. Application of the theory of absolute reaction rates to the creep failure of polymeric filaments. J Polym Sci. 1956; 20:447-55.

44. Matz DJ, Guldemond WG, Cooper SL. Delayed yielding in glassy polymers. J Polym Sci. 1972;10:1917-30.

45. Tobelsky A, Eyring $\mathrm{H}$. Mechanical properties of polymeric materials. J Chem Phys. 1943;11:125-34.

46. Janssen RPM, Govaert LE, Meijer HEH. An analytical method to predict fatigue life of thermoplastics in uniaxial loading: sensitivity to wave type, frequency and stress amplitude. Macromolecules. 2008;41:2531-40.

47. Aou K, Hsu SL, Kleiner LW, Tang F-W. Roles of conformational and configurational defects on the physical aging of amorphous poly(lactic acid). J Phys Chem. 2007;111:12322-7.

48. Adam GA, Cross A, Haward RN. The effect of thermal pretreatment on the mechanical properties of polycarbonate. J Mater Sci. 1975;10:1582-90.

49. Bauwens-Crowet C, Bauwens J-C. Annealing of polycarbonate below the glass transition: quantitative interpretation of the effect on yield stress and differential scanning calorimetry measurements. Polymer. 1982;23:1599-604.

50. Brady TE, Yeh GSY. Yielding behavior of glassy amorphous polymers. J Appl Phys. 1971;42:4622-30.

51. Rietsch F, Bouette B. The compression yield behaviour of polycarbonate over a wide range of strain rates and temperatures. Eur Polym J. 1990;26:1071-5.

52. Hamdan S, Swallowe GM. The strain-rate and temperature dependence of the mechanical properties of polyetherketone and polyetheretherketone. J Mater Sci. 1996;31:1415-23.

53. van Breemen LCA, den Hartog TM, Govaert LE, Meijer HEH. Constitutive modeling of polymer glasses: a multi-mode approach; 2008 (in preparation).

54. Klompen ETJ, Engels TAP, van Breemen LCA, Schreurs PJG, Govaert LE, Meijer HEH. Quantitative prediction of long-term failure of polycarbonate. Macromolecules. 2005;38:7009-17. 